\title{
Acid Value Determination and Pre-Esterification of Crude Euphorbia lathyris L. Oil
}

\author{
Qiuyun Zhang1,2*, Jinfeng $\mathrm{Wu}^{1}$, Peihua $\mathrm{Ma}^{3}$, Jie Cai ${ }^{4}$, Yutao Zhang ${ }^{1,2}$ \\ ${ }^{1}$ School of Chemistry and Chemical Engineering, Anshun University, Anshun, China \\ ${ }^{2}$ Special and Key Laboratory of Functional Materials and Resource Chemistry of Guizhou Provincial Education \\ Department, Anshun University, Anshun, China \\ ${ }^{3}$ School of Chemistry and Chemical Engineering, Guizhou University, Guiyang, China \\ ${ }^{4}$ School of Science, Guizhou University, Guiyang, China \\ Email: ${ }^{\text {sci qyzhang@126.com }}$
}

Received 16 March 2015; accepted 17 April 2015; published 21 April 2015

Copyright (C) 2015 by authors and Scientific Research Publishing Inc.

This work is licensed under the Creative Commons Attribution International License (CC BY).

http: //creativecommons.org/licenses/by/4.0/

(c) () Op Den Access

\section{Abstract}

There were various problems in the determination of oil acid value of the national standard method, and this paper developed a low cost, simple and effective way to determine the acid value of oil and grease. Furthermore, the esterification of high acid Euphorbia lathyris L. oil (ELO) with methanol could be efficiently catalyzed by hydrochloric acid to produce biodiesel, and the influencing factors such as the amount of catalyst, reaction time, reaction temperature and molar ratio of oil to methanol were also studied. Under the optimized conditions with the oil to methanol molar ratio of $1: 30$ and a reaction temperature of $70^{\circ} \mathrm{C}, 95.8 \%$ oil conversion was obtained within 40 min in the presence of only $2.0 \mathrm{wt} \%$ of catalyst. Therefore, the low-cost non-edible Euphorbia lathyris $\mathrm{L}$. oil as a raw material had good potential for the synthesis of biodiesel in industry.

\section{Keywords}

Acid Value, Pre-Esterification, Euphorbia lathyris L. Oil, Biodiesel

\section{Introduction}

Sustainability, in essence, is the development of methodologies to meet the needs of the present without compromising those of future generations, which has become a watchword for modern society [1]. Biodiesel, as an

\footnotetext{
${ }^{*}$ Corresponding author.
}

How to cite this paper: Zhang, Q.Y., Wu, J.F., Ma, P.H., Cai, J. and Zhang, Y.T. (2015) Acid Value Determination and PreEsterification of Crude Euphorbia lathyris L. Oil. World Journal of Engineering and Technology, 3, 70-75. 
alternative of the conventional fossil fuel, has received considerable attention in recent years due to it's free of sulphur, biodegradable and non-toxic [2] [3]. Generally, biodiesel is produced by the esterification or transesterification of free fatty acids, vegetable oil or waste oil with alcohols via homogeneous or heterogeneous catalysis [4]. However, biodiesel is not economically competitive with fossil diesel fuel in the market due to its high cost [5]. An effective way to reduce biodiesel cost is using non-edible oils, such as Euphorbia lathyris oil, Sapindus mukorossi kernel oil, and Jatropha curcas oil. However, processing non-edible feedstock containing FFAs with a base catalyst cannot be converted into fuel due to the formation of soap. Therefore, the non-edible oils should be pre-esterified before application.

Euphorbia lathyris L. active for detumescence and disinsection is an herbaceous plant of Euphorbiaceae and has been extensively researched in the field of medicine. In addition, Euphorbia lathyris L. with high oil content and adaptability to environment, which is a non-food oil crop, is one of promising species used as biodiesel feedstock [6] [7]. Unfortunately, the Euphorbia lathyris L. oil (ELO) contains large amounts of FFAs and needs to determine acid value. Recently, three methods (GB/T 5009.37 - 2003, GB/T 5530 - 2005 and SN/T 0801.19 1999) were reported to determine the acid value of the oil and grease. Since this method has some disadvantages such as complex operation, greater toxic reagents and high testing costs. Consequently, this paper attempts to develop an efficient, simple and low-cost method for the determination of acid value of oil. In addition, the ELO contains large amount of FFAs. It cannot be converted into biodiesel by the conventional alkali-catalyzed. Thus, the ELO of high acid value with methanol via pre-esterification reaction is also discussed in the paper.

\section{Experimental}

\subsection{Materials}

Euphorbia lathyris L. oil was purchased from Luodian County, Guizhou Province. Methanol (AR, >99\%), ethanol (AR), ethanol (AR, 95\%), petroleum ether (AR), diethyl ether (AR), hydrochloric acid (AR), and phenolphthalein(AR) were purchased from Sinopharm Chemical Regent Co., Ltd. All other chemicals were of analytical grade and used as received, unless otherwise noted.

\subsection{Determination of Acid Value}

A certain amount of crude ELO was added to $30 \mathrm{~mL}$ of mixed solvent (ethanol and petroleum ether). Then, 2-3 drops of phenolphthalein was added into the mixed solution and stirred for a while. $0.1 \mathrm{~mol} / \mathrm{L}$ potassium hydroxide solution was also used for calibration on the above solution. The acid value of the ELO could be determined on the basis of the following formula:

$$
\text { Acid value }=\frac{V \times C \times 56.1}{m}
$$

where $V$ is the consumption of titration $\mathrm{KOH}$ solution volume, $\mathrm{mL}$; $C$ is the concentration of $\mathrm{KOH}$ solution, $\mathrm{mol} / \mathrm{L} ; \mathrm{m}$ is the quality of the oil, g; 56.1 is potassium hydroxide molar mass, $\mathrm{g} / \mathrm{mol}$. All experiments were measured three times in parallel, and then averaged.

\subsection{Typical Procedure for Pre-Esterification Reaction}

The pre-esterification was carried out in a single-necked with a temperature controller and mechanical stirrer. Certain amounts of crude ELO, methanol and hydrochloric acid were added to the reactor, and the resulting mixture was heated to $70^{\circ} \mathrm{C}$ for $40 \mathrm{~min}$. Upon completion, the catalytic system was cooled down to the room temperature. The oil was separated from methanol layers by centrifugation. The methanol layer consisting of residual methanol, solvent, and hydrochloric acid was removed and evaluated the recoverability of these catalysts. The oil layer was analyzed by titration, and the pre-esterification conversion could be calculated using a previously reported technique [8] [9], and the calculation equation listed below:

$$
\text { conversion }(\%)=\frac{A V_{0}-A V_{1}}{A V_{0}} \times 100 \%
$$

where $A V_{0}$ is the acid value before reaction and $A V_{1}$ is the acid value after reaction. 


\section{Results and Discussion}

\subsection{Determination of Acid Value of ELO}

\subsubsection{Effect of Different Euphorbia lathyris L. Oil Mass}

The effect of oil mass on the determination of acid value is demonstrated in Table 1 . As seen in Table 1 , the acid values of different oil quality were about $31.0 \mathrm{mg} \mathrm{KOH} / \mathrm{g}$, therefore, in the actual test. In order to save oil sample, the optimum oil mass was about $0.5 \mathrm{~g}$.

\subsubsection{Effect of the Ratio of Mixed Solvent of Petroleum Ether and Ethanol}

The effect of mixed solvent of petroleum ether and ethanol on the rate for acid value was studied in Table 2. When the ratio of petroleum ether and ethanol was increased from 1:1 to 4:1, the crude ELO acid value gradually increased. However, when the ratio of petroleum ether and ethanol was 2:1, the determination result of the crude ELO acid value was 31.0 with the acid value of crude ELO itself close. Hence, all experiments were performed at 2:1 of the ratio of petroleum ether and ethanol.

\subsubsection{Effect of Dosage of Mixed Solvent}

The amount of mixed solvent also affects the determination of the acid value of crude ELO [10]. As shown in Table 3, when the amount of mixed solvent was $20 \mathrm{~mL}$, the acid value was $29.7 \mathrm{mg} \mathrm{KOH} / \mathrm{g}$, due to a little amount of mixed solvent which leads to the crude ELO concentration too high, and its insufficiency may cause a measurement error. With the amount of mixed solvent increasing from 40 to $50 \mathrm{~mL}$, the determination results of the crude ELO acid value became higher. Therefore, the amount of the mixed solvent of the determination of the acid value was optimized to be $30 \mathrm{~mL}$.

\subsubsection{This Method Was Compared with the National Standard Method in the Determination of Acid Value}

Currently, the determination of acid value used to determine the animal fats are mainly three methods (GB/T 5009.37-2003, GB/T 5530-2005 and SN/T 0801.1-1999). To investigate various national standard methods for the determination of the results, various national standard methods for the determination of the acid value of the ELO were investigated (Table 4). The results of this test method for determining the acid value was consistent with the results of various national standard methods. Moreover, compared with other method, the test method is relatively easy to operate, less solvent used, and low cost. Herein, the test method provides an accurate, reliable, simple, reagent easily save and low cost method for the fast determination of acid value of high acid value oils.

Table 1. Effect of different oil mass on the determination of acid value.

\begin{tabular}{ccccccc}
\hline ELO mass (g) & 0.4798 & 0.8741 & 1.3889 & 1.7217 & 2.3342 \\
Acid value (mg KOH/g) & 32.1 & 31.6 & 31.0 & 31.5 & 30.4 \\
\hline
\end{tabular}

Conditions: mixed solvent $\left(\mathrm{V}_{\text {Petroleum ether }}: \mathrm{V}_{\text {Ethanol }}=2: 1\right)=30 \mathrm{~mL}$.

Table 2. Effect of the ratio of mixed solvent of petroleum ether and ethanol on the determination of acid value.

\begin{tabular}{cccc}
\hline $\mathrm{V}_{\text {Petroleum ether: }} \mathrm{V}_{\text {Ethanol }}$ & $1: 1$ & $2: 1$ & $3: 1$ \\
Acid value $(\mathrm{mg} \mathrm{KOH} / \mathrm{g})$ & 31.7 & 31.0 & 32.7 \\
\hline
\end{tabular}

Conditions: ELO mass: about 0.5 g; mixed solvent $=30 \mathrm{~mL}$.

Table 3. Effect of dosage of mixed solvent on the determination of acid value.

\begin{tabular}{cccc}
\hline Solvent dosage $(\mathrm{mL})$ & 20 & 30 & 40 \\
Acid value $(\mathrm{mg} \mathrm{KOH} / \mathrm{g})$ & 29.7 & 31.6 & 33.3 \\
\hline
\end{tabular}

Conditions: ELO mass: about 0.5 g; mixed solvent: $V_{\text {Petroleum ether }}: V_{\text {Ethanol }}=2: 1$. 
Table 4. Several steps of determination method of comparison.

\begin{tabular}{|c|c|c|c|c|}
\hline Determination method & Oil mass (g) & $\begin{array}{c}\text { Solvent/mL } \\
\text { (volume ratio) }\end{array}$ & Titrant & $\begin{array}{l}\text { Acid value } \\
\text { (mg KOH/g) }\end{array}$ \\
\hline $\begin{array}{l}\text { National standard } \\
\text { GB/T 5009.37-2003 }\end{array}$ & $3.0-5.0$ & 50 mL (Diethyl ether:ethanol = 2:1) & $\begin{array}{c}0.05 \mathrm{~mol} / \mathrm{L} \mathrm{KOH} \text { aqueous } \\
\text { solution }\end{array}$ & 31.1 \\
\hline $\begin{array}{l}\text { National standard } \\
\text { GB/T 5530-2005 }\end{array}$ & 0.5 & $50 \mathrm{~mL}$ (Ethanol) & $\begin{array}{l}0.1 \mathrm{~mol} / \mathrm{L} \mathrm{KOH} \text { aqueous } \\
\text { solution }\end{array}$ & 31.1 \\
\hline $\begin{array}{l}\text { National standard } \\
\text { SN/T 0801.19-1999 }\end{array}$ & 0.5 & $\begin{array}{c}50 \text { mL (Diethyl ether:95\% } \\
\text { Ethanol = 1:1) }\end{array}$ & $\begin{array}{l}0.1 \mathrm{~mol} / \mathrm{L} \mathrm{KOH} \text { aqueous } \\
\text { solution }\end{array}$ & 31.1 \\
\hline This work & 0.5 & $30 \mathrm{~mL}$ (Petroleum ether:ethanol = 2:1) & $\begin{array}{c}0.1 \mathrm{~mol} / \mathrm{L} \mathrm{KOH} \text { aqueous } \\
\text { solution }\end{array}$ & 31.2 \\
\hline
\end{tabular}

\subsection{Influence of the Pre-Esterification Reaction Parameters}

The pre-esterification reaction could be mainly influenced by the following parameters, such as the amount of catalyst, reaction time, reaction temperature and the molar ratio of oil/methanol. The effect of those reaction parameters on the conversion of esterification was examined as shown in Figure 1.

a) Effect of catalyst amount

Figure 1(a) depicts the effect of catalyst amount on the pre-esterification of high acid value ELO over hydrochloric acid catalyst. In the absence of catalyst, the esterification conversion rate was low (less than 10\%), with the amount of catalyst increasing from 0.5 to $2.0 \mathrm{wt} \%$, the conversion raised from $66.3 \%$ to $95.8 \%$. However, the excessive amount of the catalyst led to the esterification conversion rate slightly increased. Thus, the optimum catalyst amount obtained for this reaction was $2.0 \mathrm{wt} \%$.

b) Effect of reaction time

The effect of reaction time on the conversion of the pre-esterification reaction was studied (Figure 1(b)). It is evident that the reaction conversion increased with increasing duration and reached $95.8 \%$ after 40 min. However, when the reaction time was extended to $100 \mathrm{~min}$ (the conversion reached 95.8\%), no significant increase was observed in the methyl esterification conversion. It was thought that the esterification was a reversible reaction achieving the equilibrium. Based on these data, a reaction time of 40 min was selected for further investigation.

c) Effect of reaction temperature

In addition, the effect of reaction temperature on the conversion was also studied (Figure 1(c)). The results indicated that the conversion raised with the increase of temperature from $30^{\circ} \mathrm{C}$ to $70^{\circ} \mathrm{C}$, and the conversion reached $95.8 \%$ at $70^{\circ} \mathrm{C}$; however, when reaction temperature was beyond $70^{\circ} \mathrm{C}$ (methanol refluxing temperature), the esterification reaction was not easy to operate. Therefore, the optimum reaction temperature for this reaction was $70^{\circ} \mathrm{C}$.

d) Effect of molar ratio of methanol to ELO

As shown in Figure 1(d), with the increase of molar ratio of oil/methanol from 1:15 to 1:30, the conversion increased from $87.2 \%$ to a maximum of $95.8 \%$. A further increase of the molar ratio exceeded 1:35, the conversion of ELO slightly decreased, probably because the excess of methanol diluted the reaction system, resulting in the reaction rate reduction [11]. So the molar ratio of oil/methanol was chosen as 1:30 in the experiment.

\subsection{Catalyst Reusability}

To confirm the model prediction of catalyst reuse, a reusability experiment was performed. After the reaction was completed, the product and methanol layers were isolated from the reaction system by centrifugation, and the methanol layer (containing the unreacted methanol, byproduct water, and hydrochloric acid) was recovered and then reused to next pre-esterification reaction, a known quantity of fresh methanol was added to the reaction mixture to compensate for the methanol consumed in the experiment. It could be observed that the conversion of esterification reaction of $95.8 \%, 89.4 \%$ and $66.3 \%$ was obtained as hydrochloric acid catalyst used three consecutive reactions, respectively. Such a result suggested the hydrochloric acid catalyst without a certain loss in catalytic activity after reusing for three runs, which may be due to the loss of hydrochloric acid catalyst in the mixed process. 


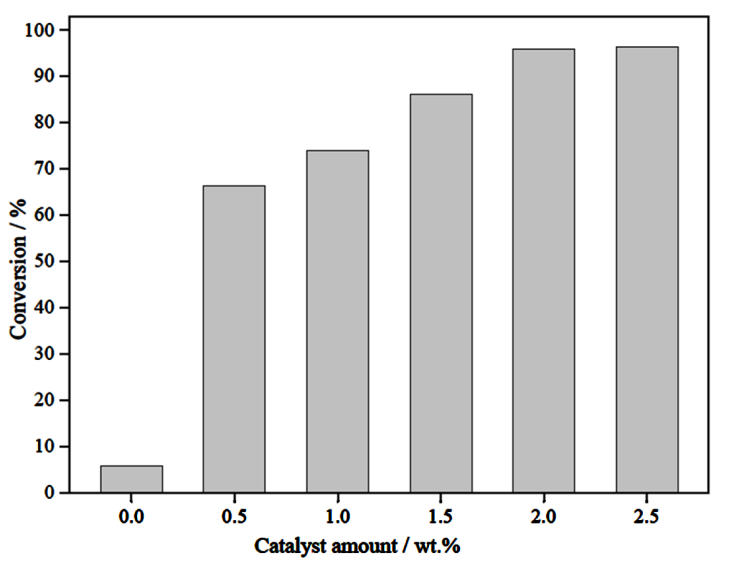

(a)

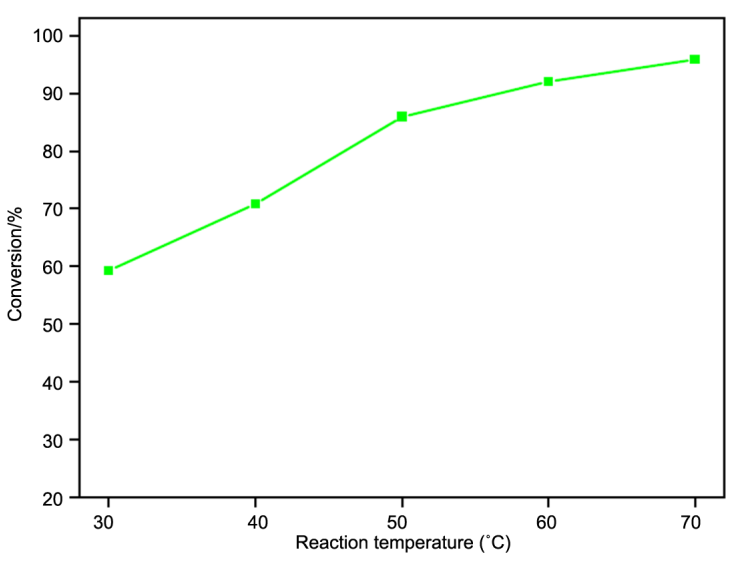

(c)

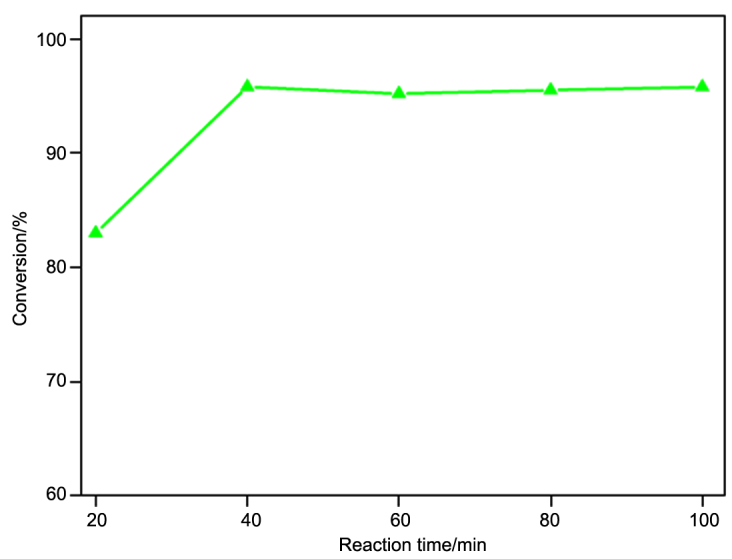

(b)

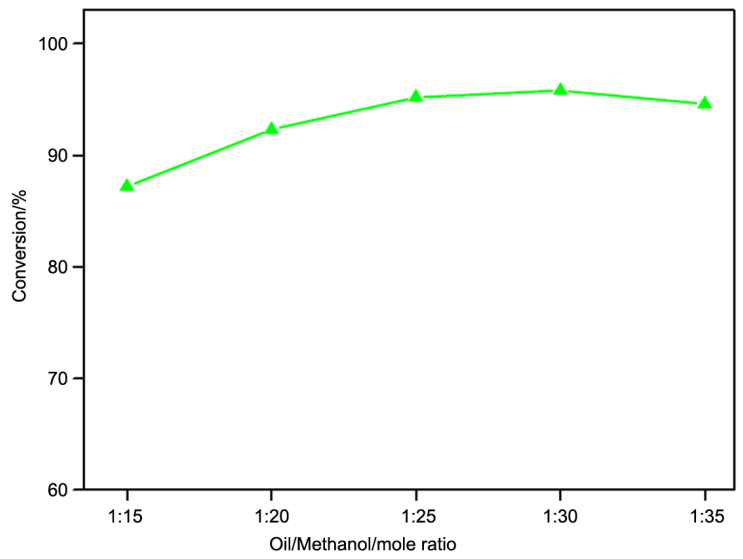

(d)

Figure 1. Effect of different reaction parameters on reaction conversion. (a) Influence of catalyst amount on conversion (molar ratio of oil to methanol $=1: 30$, reaction time $=40 \mathrm{~min}$, reaction temperature $=70^{\circ} \mathrm{C}$ ); (b) Influence of reaction time on conversion (Reaction conditions: molar ratio of Oil to methanol $=1: 30$, catalyst amount $=2.0 \mathrm{wt} \%$, reaction temperature $=$ $70^{\circ} \mathrm{C}$ ); (c) Influence of reaction temperature on conversion (molar ratio of oil to methanol $=1: 30$, catalyst amount $=2.0 \mathrm{wt} \%$, reaction time $=40 \mathrm{~min}$ ); (d) Influence of oil to methanol molar ratio on conversion (catalyst amount $=2.0 \mathrm{wt} \%$, reaction time $=40 \mathrm{~min}$, reaction temperature $=70^{\circ} \mathrm{C}$ ).

\section{Conclusions}

1) Experiments showed that optimum conditions for determination of acid value were: about $0.5 \mathrm{~g}$ ELO; 30 $\mathrm{mL}$ mixed solvent $\left(\mathrm{V}_{\text {Petroleum ether }}: \mathrm{V}_{\text {Ethanol }}=2: 1\right) ; 0.1 \mathrm{~mol} / \mathrm{L} \mathrm{KOH}$ aqueous solution. This method is simple, accurate, reliable and effective for the fast determination of acid value of oils.

2) The pre-esterification reaction of high acid value (31.2 mg KOH/g) crude Euphorbia lathyris L. oil with methanol has been conducted in this work. The optimum reaction conditions for esterification are as follows: oil to methanol molar ratio of 1:30, hydrochloric acid catalyst of $2.0 \mathrm{wt} \%$, reaction temperature of $70^{\circ} \mathrm{C}$ and reaction time of 40 min with esterification conversion of 95.8\%. Thus, the Euphorbia lathyris L.oil as a raw material is an attractive candidate for catalyzing the synthesis of biodiesel in industry.

\section{Acknowledgements}

This work was financially supported by Guizhou Province Science and Technology Department of Agricultural Science and Technology project (NZ [2013] 3029).

\section{References}

[1] Lee, A.F., Bennett, J.A., Manayil, J.C., et al. (2014) Heterogeneous Catalysis for Sustainable Biodiesel Production via 
Esterification and Transesterification. Chemical Society Reviews, 43, 7887-7916. http://dx.doi.org/10.1039/C4CS00189C

[2] Zhang, Q.Y., Li, H., Qin, W.T., et al. (2013) Solid acid Used as Highly Efficient Catalyst for Esterification of Free Fatty Acids with Alcohols. China Petroleum Processing and Petrochemical Technology, 15, 19-24. http://www.cqvip.com/QK/84331X/201301/46399418.html

[3] Sun, J., Yang, J.Y., Li, S.P., et al. (2015) Preparation and Characterization of Fluorine Modified Oxides for Transesterification. Catalysis Communications, 59, 88-91. http://dx.doi.org/10.1016/j.catcom.2014.09.014

[4] Cai, J., Zhang, Q.Y., Huang, C.M., et al. (2014) $\mathrm{ZrOCl}_{2} \cdot 8 \mathrm{H}_{2} \mathrm{O}$ : An Efficient and Cheap Catalyst for Esterification of Free Fatty Acids to Methyl Esters. China Petroleum Processing \& Petrochemical Technology, 16, 40-44. http://www.cnki.com.cn/Article/CJFDTotal-CPPP201401009.htm

[5] He, B.Q., Shao, Y.X., Ren, Y.B., et al. (2015) Continuous Biodiesel Production from Acidic Oil Using a Combination of Cation- and Anion-Exchange Resins. Fuel Processing Technology, 130, 1-6. http://dx.doi.org/10.1016/j.fuproc.2014.09.027

[6] Wei, W.L., Jin, M.Y., Ma, C., et al. (2007) Fatty Acid Composition Analysis of Euphorbia lathyris L. Seed Oil. China Oils and Fats, 32, 70-71. http://en.cnki.com.cn/Article_en/CJFDTOTAL-ZYZZ200705020.htm

[7] Liu, H., Hong, L.Z., Wang, M.W., et al. (2011) Progress of Study on Energy Plant Euphorbia lathyris L. Anhui Agriculture Science Bulletin, 17, 119-120, 134. http://en.cnki.com.cn/Article_en/CJFDTOTAL-AHNB201123052.htm

[8] Corro, G., Bañuelos, F., Vidal, E. and Cebada, S. (2014) Measurements of Surface Acidity of Solid Catalysts for Free Fatty Acids Esterification in Jatropha curcas Crude Oil for Biodiesel Production. Fuel, 115, 625-628. http://dx.doi.org/10.1016/j.fuel.2013.07.060

[9] Zhang, Q.Y., Li, H., Liu, X.F., et al. (2013) Modified Porous Zr-Mo Mixed Oxides as Strong acid Catalysts for Biodiesel Production. Energy Technology, 1, 735-742. http://onlinelibrary.wiley.com/doi/10.1002/ente.201300109/abstract

[10] Xing, L.M. (2008) Determination of Acid Study Dark Grease the New Method. Inner Mongolia Science Technology \& Economy, 8, 80-81. http://www.cqvip.com/Main/Detail.aspx?id = 27349301

[11] Song, R.L., Tong, D.M., Tang, J.Q., et al. (2011) Effect of Composition on the Structure and Catalytic Properties of KF/Mg-La Solid Base Catalysts for Biodiesel Synthesis via Transesterification of Cottonseed Oil. Energy Fuels, 25, 2679-2686. http://dx.doi.org/10.1021/ef200378j 